\title{
A facile route to encapsulate ultrasmall Ni clusters within the pore channels of AIPO-5
}

Chao Wang ${ }^{\mathrm{a}}$, Shanghua Feng ${ }^{\mathrm{a}}$, Lei Liu*a ${ }^{* a}$ Qian He ${ }^{*}$, Jinxiang Dong ${ }^{\mathrm{a}}$

${ }^{a}$ College of Chemistry and Chemical Engineering, Taiyuan University of Technology, Taiyuan, 030024, China.

${ }^{b}$ Cardiff Catalysis Institute, School of Chemistry, Cardiff University, CF10 3AT

Cardiff, $U K$

\begin{abstract}
A simple one-step method to encapsulate Ni (II) into the pore channels of AlPO-5 molecule sieve was developed by using nickel-amine complexes as templating agent for synthesis of $\mathrm{Ni}($ deta) 2 -AlPO-5. The Ni (II) occluded in the pores can be directly reduced by reducing gases in situ generated from the decomposition of nickel-amine complexes in AIPO-5 during heat treatment. The resulted catalyst has ultra-small Ni clusters highly dispersed into the pore channels, showing a high selectivity for 1,2-propanediol in the hydrogenolysis of glycerol.
\end{abstract}

Keywords Molecular sieves, Catalyst, Cluster, High-dispersion

\section{Introduction}

Zeolites have potential application in a wide range of aspects such as gas storage and separation, heterogeneous catalysis[1]. Much work regarding the utilization of zeolites as supports for metal clusters have been reported for catalytic reaction, the involved methods include liquid phase[2] and vapor phase[3] impregnation method, ion exchange with zeolites[4]. However, loading metal nanoclusters into the pores of zeolites is not a straightforward task, such difficulty originates from the microstructure of zeolites, leading to the preferable deposition of metal precursors on the outer surface.

Recently, trapping metal clusters within the pore of zeolites has aroused great 
attention as a way to enhance its dispersion and obtain the superior properties [5-7]. For example, Liu et al. [8] reported a strategy to load subnanometric Pt species within zeolite (Pt@MCM-22) during the growth of a two-dimensional zeolite into three dimensions. Wang et al. [9] reported a highly-dispersed and ultrasmall Pd clusters in silicalite-1 zeolite with superior catalytic activity under hydrothermal conditions using Pd-amine complex as precursor.

AlPO-5 as a typical aluminophosphate molecular sieve has 12-ring pore with 0.73 $\mathrm{nm}$ pore diameter, and high thermal stability $\left(>500{ }^{\circ} \mathrm{C}\right)[10]$. These features make AlPO-5 a very appropriate candidate for the encapsulation of active species for catalytic applications[3], however, encapsulating nanoclusters within AlPO-5 cannot be achieved by post-synthesis ion exchange owing to the difficulty of the neutral framework itself.

Herein, we report a facile route to obtain $\mathrm{Ni}$ nanoclusters within the porous of AlPO-5 (see Supporting Information for more experimental details). As shown in Figure $1,\left[\mathrm{Ni}(\text { diethylenetriamine })_{2}\right]^{2+}$ was used as templating agent and $\mathrm{Ni}$ precursor for the direct synthesis of AlPO-5 material with $\mathrm{Ni}$ (II) in its pore channels, $\mathrm{Ni}(\text { deta) })_{2}$-AlPO-5. Ni (II) will then be in situ reduced by the reducing gases from the decomposition of organic precursors upon calcination, and highly dispersed inside the porous support structure.

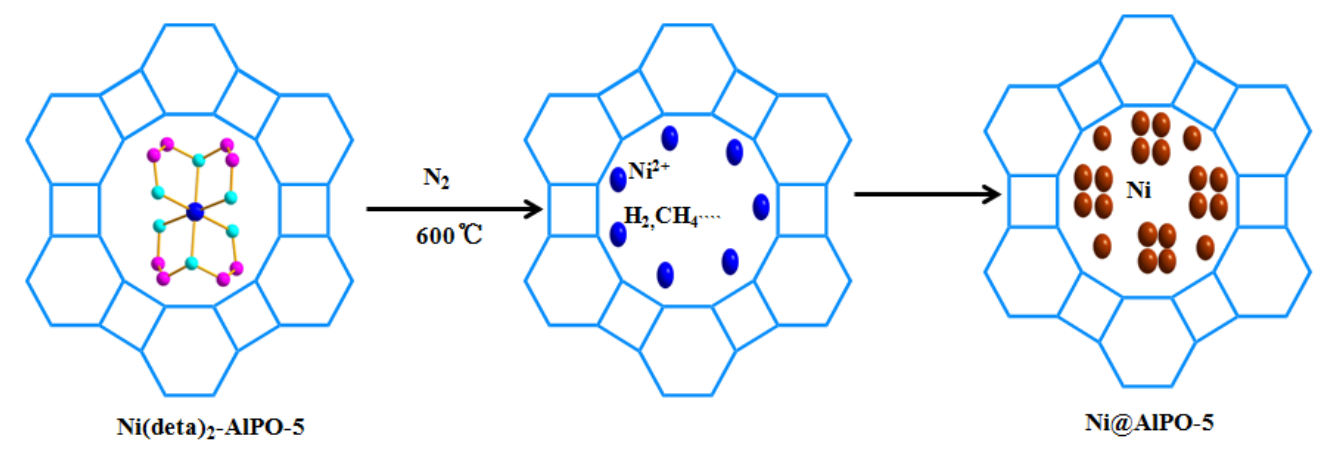

Figure 1 Schematic illustration of the formation of Ni@AlPO-5 via in situ template removal and $\mathrm{Ni}(\mathrm{II})$ reduction from $\mathrm{AlPO}-5$ with nickel-amine complexes in its pore channels upon the heat treatment under $\mathrm{N}_{2}$ atmosphere

\section{Results and discussion}


Powder XRD pattern was used to confirm the phase and purity of the materials. As shown in Figure 2, the diffraction peaks and peak positions for Ni(deta) 2 -AlPO-5 are identical to the reported one, $\left(\mathrm{Ni}(\operatorname{deta})_{2}\right)_{2} \mathrm{Al}_{24} \mathrm{P}_{24} \mathrm{O}_{96} \mathrm{~F}_{4}[11]$, which has been confirmed as a distorted variant of AlPO-5 with AFI zeolite topology. After the heat treatment under $\mathrm{N}_{2}$ atmosphere, $\mathrm{Ni}($ deta) 2 -AlPO-5 transforms into hexagonal phase [12], the typical AlPO-5 with AFI framework type, labeled as Ni@AlPO-5. The diffraction peaks for metallic Ni at $2 \theta$ of $44^{\circ}, 52^{\circ}$, and $76^{\circ}$ could not be observed after the heat treatment, presumably associated with high dispersion of Ni species in AlPO-5.

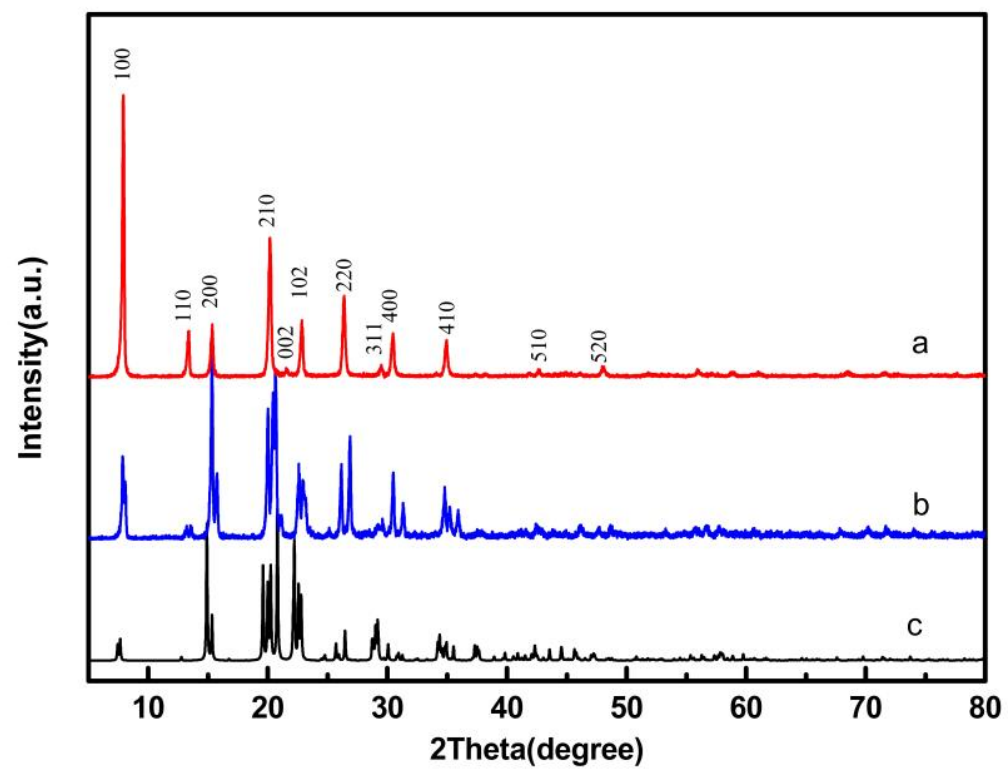

Figure 2 Powder XRD patterns of (a) Ni@AlPO-5 after calcination, (b) as-synthesized $\mathrm{Ni}(\text { deta })_{2}-\mathrm{AlPO}-5$ and (c) the standard patterns of Ni(deta) $)_{2}-\mathrm{AlPO}-5$ [11].

To verify the valence state of $\mathrm{Ni}$ species in AlPO-5 after heat-treatment, XPS analysis on Ni@AlPO-5 was performed. As shown in Figure S2, the binding energy of Ni $2 P_{3 / 2}$ and Ni $2 P_{1 / 2}$ for Ni@AlPO-5 were located at around $852.8 \mathrm{eV}$ and 870.2 $\mathrm{eV}$ respectively, corresponding to the characteristic peaks of zero-valent $\mathrm{Ni}$ species. XPS results show that most of the Ni (II) ions in AlPO-5 could be reduced during the heat treatment under $\mathrm{N}_{2}$ atmosphere.

To better understand the reduction process of Ni (II) ions during the heat treatment under $\mathrm{N}_{2}$ atmosphere, TG-MS analysis was employed to detect low molecular weight gas products decomposed from the nickel-amine complexes occluded in the pore 
channels of $\mathrm{Ni}(\text { deta) })_{2}$-AlPO-5. There is an obvious weight loss of about 7 wt $\%$ between 400 and $470^{\circ} \mathrm{C}$ companied with endothermic peak (Figure S3a), corresponding to the decomposition of nickel-amine complexes. It should be noted that some low molecular weight gas such as $\mathrm{H}_{2}, \mathrm{CH}_{4}$ and $\mathrm{C}_{3} \mathrm{H}_{9} \mathrm{~N}$ could be detected within this temperature range as shown in Figure S3b. It could be expected that the $\mathrm{Ni}$ (II) ions in the pore channels can be reduced by the reducing gases in situ generated from the nickel-amine complexes as shown schematically in Figure 1.

The Ni distribution was studied using TEM. As shown in Figure 3, two kinds of Ni species can be found on the support: i) relatively larger particles that are about $20 \mathrm{~nm}$ in size. These are the minority species and they are likely to be exposed to the surface, as some of the particles are found to be on the edge of the support (highlighted via a black arrow); ii) the majority of the Ni species are smaller particles around $5 \mathrm{~nm}$ in size, as highlighted by white arrows in Figure 3(a). Although the AlPO-5 is highly e-beam sensitive, lattice fringes of the AlPO-5 were observed, as shown in the center region of the Figure 3(b), while the thinner edge of the support appeared to be amorphous due to e-beam damage. Elongated particles that confined by the AlPO-5 lattice was found, as highlighted via a white arrow in Figure 3(b), suggesting that at least some of these types of particles are largely confined within the support channels. The proposed confinement effect is consistent with the finding that the particles in the Ni/AlPO-5 catalyst prepared by regular impregnating route are much larger (Figure 3(c)), and there are no small particles visible on the support (highlighted via a white arrow).
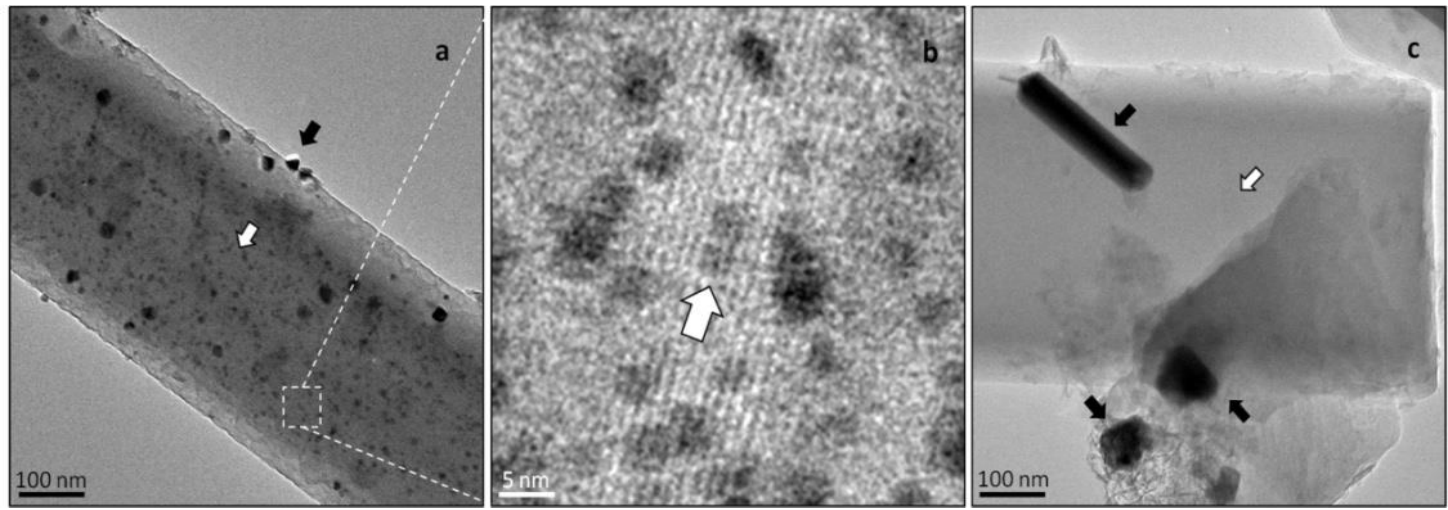

Figure 3 Representative TEM images of (a, b) Ni@AlPO-5 and (c) Ni/AlPO-5 catalysts. 
It should be noted that these smaller Ni particle size observed on TEM images for $\mathrm{Ni} @ \mathrm{AlPO}-5$ is larger than the pore size of the AlPO-5 $(0.73 \mathrm{~nm})$. Therefore, some breakage of the framework can be expected, which may give Ni particles access to the reactant. However, such breakage is limited, as Ni@AlPO-5 catalyst still has a typical AFI framework type as confirmed by XRD pattern (Figure 2). The organic species occluded in the pore channels have been completely removed during the heat treatment, which was verified by the comparison of TG analysis and FT-IR between the Ni(deta) 2 -AlPO-5 and Ni@AlPO-5 samples (Figure S4 and S5). However, the BET surface area of Ni@AlPO-5 is only $3.86 \mathrm{~m}^{2} / \mathrm{g}$, resulting from that most of the Ni clusters are located in the pore channels and block the entrance of $\mathrm{N}_{2}$ molecule. This result also indicates that most of the Ni clusters are located inside the pore channels of AlPO-5 for Ni@AlPO-5 catalyst. For comparison, the Ni/AlPO-5 with the same Ni loading amount (3.8wt\%) to Ni@AlPO-5 was prepared by wet impregnation method (see Supporting Information). It has been found that Ni/AlPO-5 still has some porosity although the BET surface area was decreased to $138.8 \mathrm{~m}^{2} / \mathrm{g}$ from $245.5 \mathrm{~m}^{2} / \mathrm{g}$ after Ni metals were supported on AlPO-5, which also supports our claim that most of the Ni particles are dispersed on the external crystal surface of AlPO-5 for Ni/AlPO-5 catalyst.

Hydrogenolysis of glycerol was selected as probe reaction to investigate the activity of studied samples (Table S1). It was found that 1,2-PDO is the main product over Ni@AlPO-5 and Ni/AlPO-5 catalyst, respectively. Compared to the Ni/AlPO-5, the Ni@AlPO-5 has a lower conversion of glycerol with 5.06\% after $12 \mathrm{~h}$ reaction but with a higher selectivity for 1,2-PDO (92.68\%). The lower catalytic activity for Ni@AlPO-5 can be understood as most of the Ni clusters are located inside the pore channels of AlPO-5 and therefore the contact between the Ni clusters and glycerol molecules are more limited. In contrast, for Ni/AlPO-5 catalyst with relatively larger Ni particles located on the outer surface of AlPO-5, gives relatively higher glycerol conversion (30.15\%) but much lower selectivity towards 1,2-PDO.

The above catalytic results also provide the evidence that most of the Ni clusters are located inside the pore channels of AlPO-5 for Ni@AlPO-5 catalyst, but the high 
loading amount of $\mathrm{Ni}(3.8 \mathrm{wt} \%)$ results in the relatively poor accessibility between the glycerol molecules and Ni species. Further improvements can be expected if the amount of nickel-amine complexes introduced into AlPO-5 can be reduced to a low value, Ni clusters with higher dispersion and even single-atom dispersion would probably be achieved owing to the pore confinement effects.

\section{Conclusions}

In conclusion, we have developed a facile strategy for the preparation of Ni@AlPO-5 catalyst with small Ni clusters located in the pore structure of AlPO-5. The $\mathrm{Ni}(\mathrm{II})$ ions could be in situ reduced by reducing gases generated from the organic precursors during the heat treatment, which gives high dispersion of $\mathrm{Ni}$ within the pore channels of the support. This approach adopted is envisaged to open a new opportunity in the development of highly active heterogeneous catalysts for advanced catalysis application.

\section{Acknowledgement}

This work was financially supported by the National Natural Science Foundation (21276174, 21322608), Program for the Innovative Talents of Higher Learning Institutions of Shanxi and A Foundation for the Author of National Excellent Doctoral Dissertation of PR China (No.201350). Q. H. would like to thank the support from Cardiff Catalysis Institute and the School of Chemistry in Cardiff University.

\section{References}

[1] M. Moliner, C. Martínez, A. Corma, Synthesis Strategies for Preparing Useful Small Pore Zeolites and Zeotypes for Gas Separations and Catalysis, Chem. Mater., 26 (2014) 246-258.

[2] J. Lu, C. Aydin, N.D. Browning, B.C. Gates, Imaging isolated gold atom catalytic sites in zeolite NaY, Angew. Chem.Int. Ed, 51 (2012) 5842-5846.

[3] S.B. Hong, E. Mielczarski, M.E. Davis, Aromatization of hexane by platinum-containing molecular sieves. I. Catalyst preparation by the vapor phase impregnation method, J. Catal., 134 (1992) 349-358..

[4] J.D. Kistler, N. Chotigkrai, P.-H. Xu, B. Enderle, P. Praserthdam, C.Y. Chen, N.D. 
Browning, B.C. Gates, A single-site platinum CO oxidation catalyst in zeolite KLTL: microscopic and spectroscopic determination of the locations of the platinum atoms, Angew. Chem.Int. Ed., 53 (2014) 8904-8907.

[5] B. Smit, T.L. Maesen, Towards a molecular understanding of shape selectivity, Nature., 451 (2008) 671-678.

[6] W.Z. Choi M, Iglesia E., Mercaptosilane-assisted synthesis of metal clusters within zeolites and catalytic consequences of encapsulation, J. Am. Chem. Soc., 132 (2010) 9129-9137.

[7] S. Goel, S.I. Zones, E. Iglesia, Encapsulation of metal clusters within MFI via interzeolite transformations and direct hydrothermal syntheses and catalytic consequences of their confinement, J. Am. Chem. Soc., 136 (2014) 15280-15290.

[8] L. Liu, U. Diaz, R. Arenal, G. Agostini, P. Concepcion, A. Corma, Generation of subnanometric platinum with high stability during transformation of a $2 \mathrm{D}$ zeolite into 3D, Nat. Mater., 16 (2017) 132-138.

[9] N. Wang, Q. Sun, R.-S. Bai, X. Li, G.-Q. Guo, J.-H. Yu, In Situ Confinement of Ultrasmall Pd Clusters within Nanosized Silicalite-1 Zeolite for Highly Efficient Catalysis of Hydrogen Generation, J. Am. Chem. Soc., 138 (2016) 7484-7487.

[10] R.J. Kalbasi, E. Izadi, Hydrothermal synthesis of pure $\mathrm{AlPO}_{4}-5$ without fluoride medium: synthesis, characterization and application as a support, J. Porous. Mater., 20 (2012) 547-556.

[11] R. Garcia, I.J. Shannon, A.M. Slawin, W.-Z. Zhou, P.A. Cox, P.A. Wright, Synthesis, structure and thermal transformations of aluminophosphates containing the nickel complex $\left[\mathrm{Ni} \text { (diethylenetriamine) }{ }_{2}\right]^{2+}$ as a structure directing agent, Micro. Meso. Mater., 58 (2003) 91-104.

[12] Ch.Baerlocher, L.B. McCusker, D.H. Olson, Atlas of Zeolite Framework Types Sixth ed. Elsevier, Netherlands, 2007. 